\title{
Electron Beam Guns for High Energy Electron Accelerators: An Overview
}

\author{
Munawar Iqbal $^{1,2}$, Ghalib UI Islam ${ }^{1}$, Muhammad Ayub Faridi ${ }^{1}$, Zusheng Zhou $^{2}$ \\ ${ }^{1}$ Centre for High Energy Physics, University of the Punjab, Lahore, Pakistan \\ ${ }^{2}$ Institute of High Energy Physics, Chinese Academy of Sciences, Beijing, China \\ Email: muniqbal.chep@pu.edu.pk
}

Received July 26, 2013; revised August 29, 2013; accepted September 24, 2013

Copyright (C) 2013 Munawar Iqbal et al. This is an open access article distributed under the Creative Commons Attribution License, which permits unrestricted use, distribution, and reproduction in any medium, provided the original work is properly cited.

\begin{abstract}
Thermionic electron beam is a fundamental part of all types of linear accelerators around the world in the field of Experimental High Energy Physics. Thermionic beam is very inexpensive and simple to produce. In this work, we give an overview of generation, design and applications of the electron beam with particular reference to e-beam generation at high energy linear accelerators. Experimental data are presented in tabular form for ready reference. We also make an evaluation of these high energy sources with our in-house designed e-beam gun. Finally, a comparison has been presented in terms of characteristic parameters of all these high performance sources.
\end{abstract}

Keywords: E-Beam Guns; LINAC; Emittance; Beam Current

\section{Introduction}

Electron beam gun is a basic component of linear accelerators (Linacs) which have a variety of applications in research (particularly in high energy and medical physics) and industry. In studying electron-positron physics, ebeam is the necessary ingredient. This is normally achieved through thermionic emission of electrons though several other modes of e-beam generation also exist. This type of emission has two modes: temperature and space charge limited emission. In first type, the emission is limited by the temperature of the cathode materials while the latter emission is limited by the space charge around the cathode due to insufficient acceleration potential. In view of its economy and ease in fabrication, continuing efforts are ongoing for the development of high energy thermioic electron gun for next generation linear accelerators. These guns require comparatively low vacuum and have long duty cycles. A detailed literature on these types of the guns can be viewed in the reference [1]. In the present study, electron beam guns used in some of the leading high energy physics laboratories are briefly described. Except SLAC, all sources under considerations are thermionic in nature. We also present one of our indigenously made source for comparison and analysis with the existing sources.

\section{The SLAC Electron Gun}

The Stanford Linear Accelerator Centre (SLAC) is a Radio Frequency (RF) linear accelerator. It was the longest linear accelerator of the World having length of about 3 kilometers with a capacity to accelerate electrons up to $50 \mathrm{GeV}$. The electron gun for SLAC is a spherical diode gun having two cylindrical Pierce type electrodes with a $20 \mathrm{~mm}$ diameter semiconductor photocathode. It has 0.18 $\mathrm{mm}$ thick molybdenum focusing electrodes. The gun consists of a grounded vacuum flange on which anode is mounted and on the right side is a rear deck insulated from vacuum flange by using alumina ceramic insulators which were kept at cathode potential. Corona shields were placed on the anode flange, which prevented the arcing. coaxial shaped filament was made from Tantalum and was clamped by using two tantalum screws. The filament to cathode distance was adjustable due to spacers placed at back of the filament. At an acceleration potential of 120 $200 \mathrm{kV}$ between cathode and anode, beam current of $15 \mathrm{~A}$ was obtained [2-4]. The electron gun assembly is shown in Figure 1. The main specifications of the electron gun are summarized in Table 1.

\section{The BEPCII Electron Gun}

The Beijing Electron-Positron Collider (BEPC) is located 
Table 1. Characteristics of SLAC electron gun [2-4].

\begin{tabular}{cc}
\hline Parameters & Specifications \\
\hline Gun type & Spherical diode gun \\
Cathode & GaAs photo cathode of $20 \mathrm{~mm}$ diameter \\
Acceleration potential & $120-200 \mathrm{kV}$ \\
Beam current & $15 \mathrm{~A}$ \\
Grid bias voltage & $0-1000 \mathrm{~V}$ \\
Pulse width & $2 \mathrm{nsec}$ \\
Repetition rate & $120 \mathrm{~Hz}$ \\
Beam emittance & $11.4 \pi \mathrm{mm}-\mathrm{mrad}$ \\
Perveance & $0.1 \mu \mathrm{A} / \mathrm{V}^{3 / 2}$ \\
Pressure & $10^{-11} \mathrm{Torr}$ \\
\hline
\end{tabular}

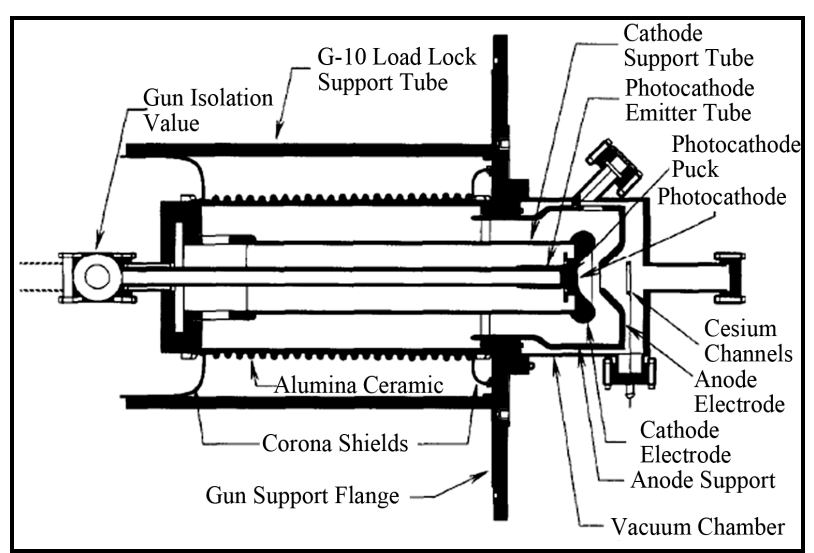

Figure 1. Cross sectional view of SLAC gun [2].

in the Institute of High Energy Physics (IHEP), Beijing, China. It has an RF linear accelerator up to 202 meters length. Initially, BEPC accelerated electrons up to $2 \mathrm{GeV}$ (BES II). Later on, it was up-graded to BEPCII. The BEPCII electron gun is a thermionic triode electron gun as shown in Figure 2.

Cathode-grid assembly for this gun is EIMAC Y796 (Osmium coated). For a normal operation of the gun, a power supply of $0-50 \mathrm{~W}$ heating power, at $6 \mathrm{~V}$ filament voltage, was used to heat the cathode. With an acceleration potential of $150 \mathrm{kV}$, beam current of $10 \mathrm{~A}$ was obtained. Gun emittance was measured to be $16 \pi \mathrm{mm}-$ mrad [5-9]. Schematic diagram of electron gun with avalanche pulsar is shown in Figure 2. Electron gun specifications are summarized in Table 2.

\section{The KEK Electron Gun}

High Energy Accelerator Research Organization also known as KEK is a research organization in Tsukuba, Ibaraki, Japan [10]. Electron gun for the injection system of KEK 2.5 GEV linac is a gridded oxide coated triode
Table 2. Characteristics of BEPCII electron gun [5-9].

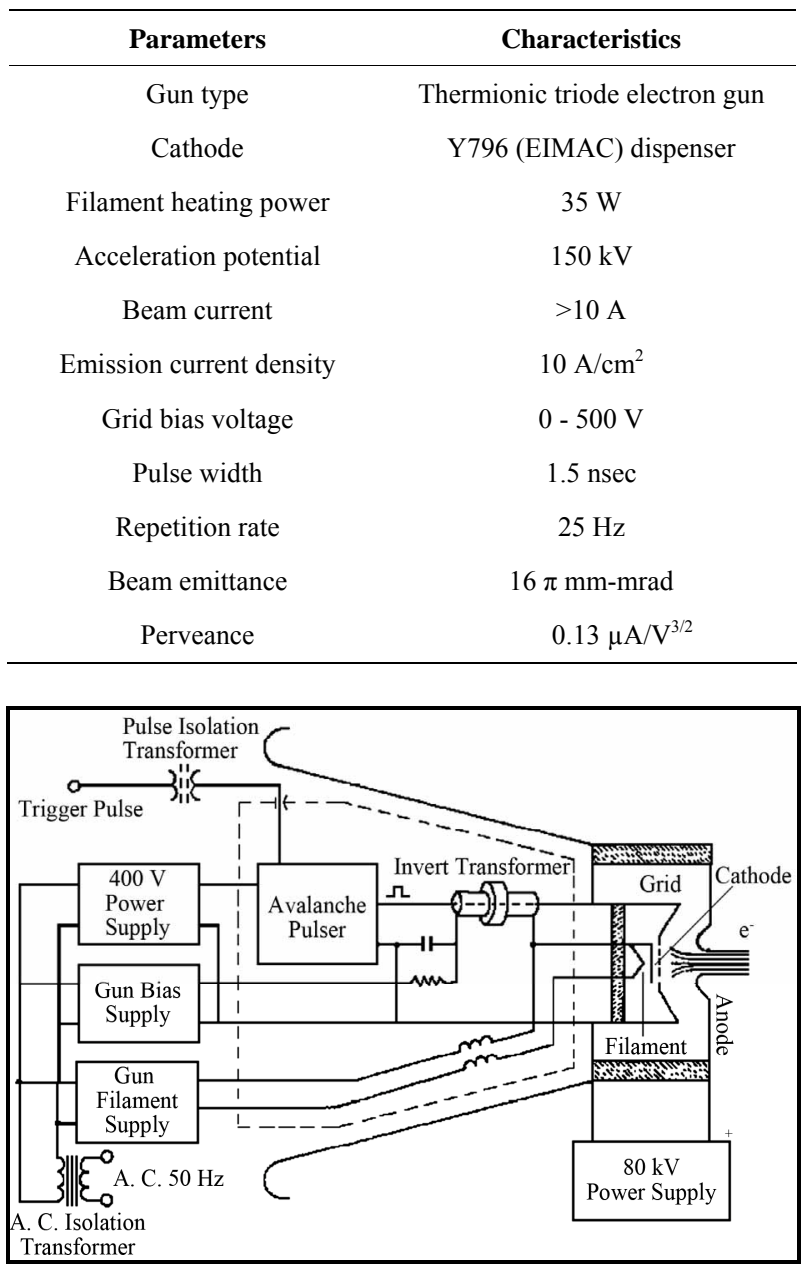

Figure 2. Schematic of electron gun with avalanche pulsar [8].

electron gun. Its cathode is an Osmium coated Y-796 (EIMAC) with $10 \mathrm{~mm}$ diameter. The cathode to grid distance was kept $0.18 \mathrm{~mm}$. The gun has a small vacuum flange and is mounted on an assembly stem [11,12]. A cross sectional view of the electron gun assembly is shown in Figure 3.

Cathode to anode distance was kept $(24 \pm 0.5) \mathrm{mm}$. The gun worked in space charge limited mode at filament voltage of $6.3 \mathrm{~V}$ and the measured temperature was $810^{\circ} \mathrm{C}$. For this gun, at an acceleration potential of $180 \mathrm{kV}$, the maximum beam current of $10 \mathrm{~A}$ was obtained. The gun design and output parameters are summarized in the Table 3 .

\section{The Line Source Electron Gun}

This is an indigenously fabricated gun that has an ever long filament of $14 \mathrm{~cm}$ in length; therefore called the line e-gun. The filament is made of Tungsten wire of $1 \mathrm{~mm}$ diameter. Its focusing electrodes (FE) are at cathode po- 
Table 3. Characteristics of KEK electron gun [11,12].

\begin{tabular}{cc}
\hline Parameters & Specifications \\
\hline Gun type & Thermionic, pulsed, Gridded Oxide triode \\
Filament voltage & $6.3 \mathrm{~V}$ \\
Acceleration potential & $180 \mathrm{kV}$ \\
Beam current & $10 \mathrm{~A}$ \\
Emission current density & $12 \mathrm{~A} / \mathrm{cm}^{2}$ \\
Pulse width & $10 \mathrm{nsec}$ \\
Beam emittance & $14 \pi \mathrm{mm}-\mathrm{mrad}$ \\
Perveance & $0.13 \mu \mathrm{A} / \mathrm{V}^{3 / 2}$ \\
Pressure & $3 \times 10^{-9} \mathrm{Torr}$ \\
\hline
\end{tabular}

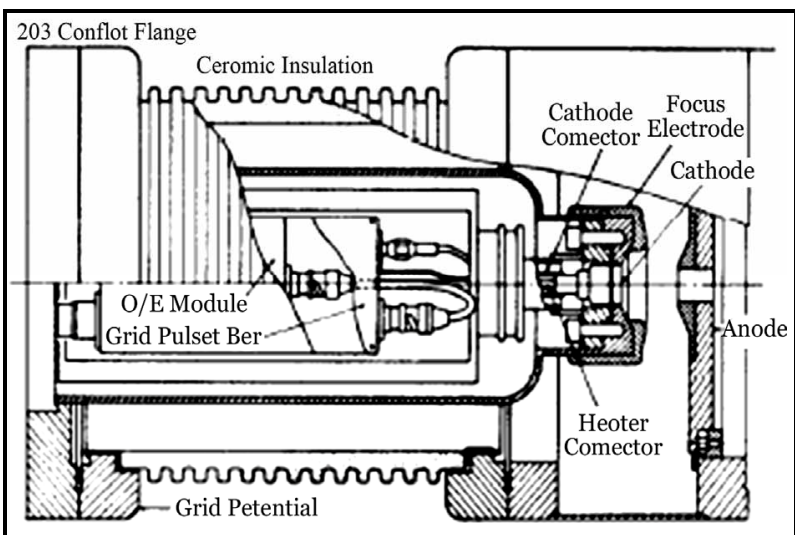

Figure 3. Cross-sectional view of the KEK electron gun [11].

tential, and are positioned vertically with respect to cathode and grounded anodes. Anode has an opening of 7.5 $\mathrm{mm}$ with an acceleration gap between the cathode and the anode of $7.5 \mathrm{~mm}$. In order to keep the long filament in its original shape, we introduced a spring action mechanism through the spring assembly. FE and anode were made from $1 \mathrm{~mm}$ Tantalum sheet. Above FE, anode is placed at $4 \mathrm{~mm}$ away and is grounded with high voltage alumina insulators. The gun was tested up to $50 \mathrm{~kW}(5000 \mathrm{~mA} \times$ $10 \mathrm{kV}$ ) and achieved power density of $33 \mathrm{~kW} / \mathrm{cm}^{2}$ at the target $[13,14]$. A cross sectional view of the gun is shown in Figure 4.

Due to proper shielding of the gun components as well as the cap to source assembly; the gun was operated swiftly for several hours continuously. The gun has the capability to operate even for higher acceleration voltage to achieve higher beam currents. Main parameters of the gun are summarized in Table 4.

The graphical representation of the comparison is given in Figure 5.

\section{Conclusion}

Summary of design and output characteristics parameters of the above said guns is presented in Table $\mathbf{5}$ and shown
Table 4. Characteristics of line source electron gun.

\begin{tabular}{cc}
\hline Parameters & Characteristics \\
\hline Gun type & Thermionic diode gun \\
Cathode & Tungsten wire of $140 \mathrm{~mm}$ length \\
Filament heating power & $600 \mathrm{~W}$ \\
Acceleration potential & $10 \mathrm{kV}$ \\
Beam current & $5 \mathrm{~A}$ \\
Output power & $50 \mathrm{~kW}$ \\
Beam emittance & $70 \pi \mathrm{mm}-\mathrm{mrad}$ \\
Perveance & $5 \mu \mathrm{A} / \mathrm{V}^{3 / 2}$ \\
Pressure & $5 \times 10^{-5} \mathrm{Torr}$ \\
\hline
\end{tabular}

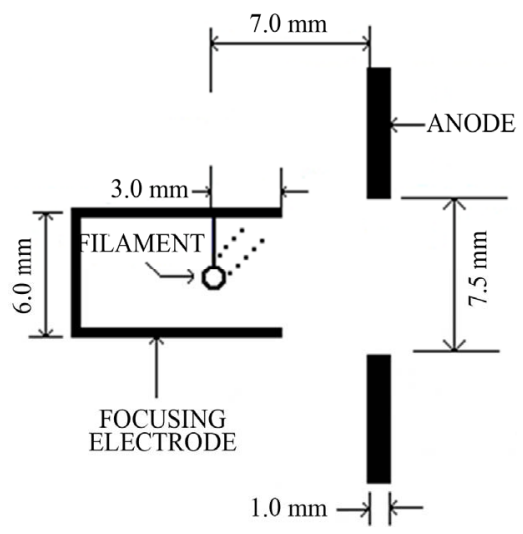

Figure 4. Line source electron gun.

Table 5. Performance parameters of electron guns of high energy accelerators.

\begin{tabular}{cccc}
\hline Gun Type & $\begin{array}{c}\text { Acceleration } \\
\text { Potential (kV) }\end{array}$ & $\begin{array}{c}\text { Beam Current } \\
\text { (Amp) }\end{array}$ & $\begin{array}{c}\text { Emittance } \\
\text { (Pi mm-mRad) }\end{array}$ \\
\hline SLAC & 200 & 15 & 11.4 \\
KEK & 180 & 10 & 14 \\
BEPCII & 150 & 10 & 16 \\
Line gun & 10 & 5 & 70 \\
\hline
\end{tabular}

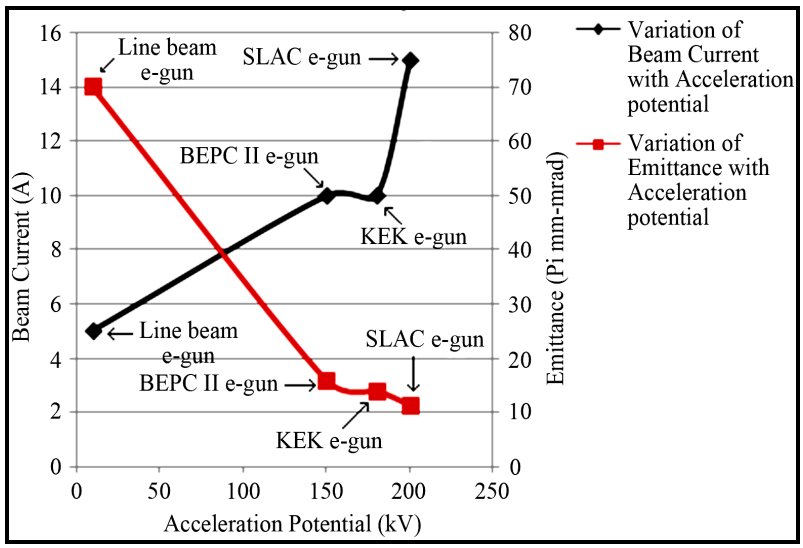

Figure 5. Variation of beam current and emittance with acceleration potential. 
in Figure 5. The data determined that acceleration potential is a responsible parameter to enhance the beam current and decrease in emittance of the gun which is an ultimate goal to develop electron sources for high energy electron accelerators. The study also revealed that line e-gun (our gun) reached a beam current of $5 \mathrm{~A}$ at an acceleration potential of $10 \mathrm{kV}$ only. Hence, half of the beam current is obtained at 15 - 20 times less than acceleration potential in comparison. The first three sources are pure that are use for high energy accelerators to study the fundamental physics of the elementary particles. However, the last one is a potential candidate to be used for the accelerators and currently being utilized extensively for nanotechnology applications for thin film development on industrial scale. Moreover, the SLAC source utilized higher vacuum and acceleration potential that required high operational cost.

\section{REFERENCES}

[1] M. Iqbal, "Development \& Applications of High Power Thermionic Electron Beam Sources," Ph.D Thesis, CHEP, 2007.

[2] R. Alley, et al., Nuclear Instruments and Methods in Physics Research Section A, Vol. 365, 1965, p. 1.

[3] D. Shultz, et al., "The Polarized Electron Source of the Stanford Linear Accelerator Centre," SLAC-PUB-6606, 1994.
[4] C. K. Sinclair and R. H. Miller, "A High Current, Short Pulse, RF Synchronized Electron Gun for the Stanford Linear Accelerator," SLAC-PUB-2705, 1981.

[5] F. A. Harris, Nuclear Physics B-Proceedings Supplements, Vol. 162, 2006, pp. 345-350. http://dx.doi.org/10.1016/j.nuclphysbps.2006.09.119

[6] P. Guoxi, Proceedings of LINAC, Knoxville, 20-25 August 2006, p. 55.

[7] B. Liu, et al., Proceedings of 2005 Particle Accelerator Conference, Knoxville, 16-20 May 2005, p. 1.

[8] M.-P. Gu, et al., IEEE Transaction on Nuclear Science, Vol. 30, 1983, pp. 2962-2964. http://dx.doi.org/10.1109/TNS.1983.4336540

[9] B. Liu, M.-P. Gu, et al., High Energy Physics \& Nuclear Physics, Vol. 30, 2006, p. 466.

[10] http://www.kek.jp/intra-e/about/whatskek.html

[11] S. Fukuda, et al., Particle Accelerators, Vol. 27, 1990, p. 145.

[12] S. Ohsawa, et al., KEK Pre-Print, 1992, pp. 92-132.

[13] M. Iqbal, et al., Review of Scientific Instruments, Vol. 74, 2003, p. 4616. http://dx.doi.org/10.1063/1.1614852

[14] M. Iqbal and Fazal-e-Aleem, Review of Scientific Instruments, Vol. 77, 2006, Article ID: 106101. http://dx.doi.org/10.1063/1.2349608 